\title{
Pharmacogenomic Study
}

National Cancer Institute

\section{Source}

National Cancer Institute. Pharmacogenomic Study. NCI Thesaurus. Code C49661.

A study of identification and analysis of genomic variations that affect the efficacy of a drug. Pharmacogenomic studies can potentially be predictive of an individual's drugresponse or adverse reactions or susceptibility to iatrogenic disorders, and may also reveal new targets that can help in the design of new drugs. 